GA-A24453

\title{
PREPARATION OF CU-DOPED GLOW DISCHARGE POLYMER COATINGS FOR ICF APPLICATIONS
}

\author{
by \\ A. NIKROO, E. CASTILLO, D.W. HILL, \\ and A.L. GREENWOOD
}




\section{DISCLAIMER}

This report was prepared as an account of work sponsored by an agency of the United States Government. Neither the United States Government nor any agency thereof, nor any of their employees, makes any warranty, express or implied, or assumes any legal liability or responsibility for the accuracy, completeness, or usefulness of any information, apparatus, product, or process disclosed, or represents that its use would not infringe privately owned rights. Reference herein to any specific commercial product, process, or service by trade name, trademark, manufacturer, or otherwise, does not necessarily constitute or imply its endorsement, recommendation, or favoring by the United States Government or any agency thereof. The views and opinions of authors expressed herein do not necessarily state or reflect those of the United States Government or any agency thereof. 


\title{
PREPARATION OF CU-DOPED GLOW DISCHARGE POLYMER COATINGS FOR ICF APPLICATIONS
}

\author{
by \\ A. NIKROO, E. CASTILLO, D.W. HILL, \\ and A.L. GREENWOOD
}

This is a preprint of a paper presented at the 15th Target Fabricartion Specialists Meeting, Gleneden Beach, Oregon, June 1-5, 2003 and to be published in Fusion Science and Technology.

\author{
Work supported by \\ the U.S. Department of Energy \\ under Contract No. DE-AC03-01SF22260
}

GENERAL ATOMICS PROJECT 30095

SEPTEMBER 2003 


\title{
PREPARATION OF CU-DOPED GLOW DISCHARGE POLYMER COATINGS FOR ICF APPLICATIONS
}

\author{
A. Nikroo, E. Castillo, D. Hill, A.L. Greenwood \\ General Atomics, P.O. Box 85608, San Diego, California 92186-5608 \\ email: nikroo@gat.com
}

Copper doped polymer shells can provide a very useful diagnostic for fast ignition experiments currently being performed at various laboratories around the world. The low concentration copper dopant acts as an efficient $x$-ray source providing information on the physics of fast ignition. We have developed copper doped glow discharge (GDP) coatings suitable for such purposes. Copper acetylacetonate (CuAcAC), a solid at room temperature, was used in a heated jacket as the dopant source. We used this technique to fabricate thin ( 5-7 $\mu \mathrm{m})$ GDP shells doped with $\sim 1$ at \% copper through the depolymerizable mandrel process for fast ignition experiments. The details of the experimental set up and the range and limitations of the technique are discussed.

\section{INTRODUCTION}

GDP coatings have been the work-horse of ICF target fabrication for over ten years now. ${ }^{1,2}$ GDP is deposited by dissociating and reacting a hydrocarbon gas in an inductively coupled plasma generated using a specially designed radio frequency reactor. ${ }^{3}$ Hydrogen is also added to the process to obtain thick films $(>50 \mu \mathrm{m})$ appropriate for ICF applications with superior surface finish ( $1 \mathrm{~nm}$ RMS) and low stress. The deposited material has the nominal chemical formula of $\mathrm{CH}_{1.3}$. By changing the process gases the chemical nature of these coatings can be changed. For example, if deuterated analogs of the hydrocarbon gases are used then deuterated polymer films can be produced with nominal chemical formula of $C D_{1.5}$. The simple deuteration of films requires rather minor modifications to the coating process. Over the years, in addition to deuteration of GDP, several higher $\mathrm{Z}$ dopants have been incorporated in GDP coatings as well. These include germanium, ${ }^{4}$ chlorine 5 and beryllium 6 among others. Incorporation of such dopants is more involved as a gas or vapor containing the higher $\mathrm{Z}$ element needs to be introduced to the coating process. In addition to modification of the gas delivery manifold of the coater, a proper dopant material needs to be identified which contains the required high $\mathrm{Z}$ element. This dopant needs to be either gaseous or have enough vapor pressure at reasonable temperatures to allow proper delivery of the material to the plasma reactor. Additionally, the deposited doped $\mathrm{CH}$ material has to be sufficiently stable that the film survives post processing such as routine characterization without requiring prohibitively involved handling requirements. For example, Ti-doped GDP is stable up to $\sim 5$ at $\%$ doping beyond which the films disintegrate upon very short ( $\sim$ minutes) exposure to oxygen in ambient air.

In this paper we report on extension of the GDP doped coatings to copper doped GDP. These films are of interest in the fast ignition area. In particular, $\mathrm{Cu}$-doped deuterated shells, $\mathrm{Cu}-\mathrm{CD}$, are desired for possibly following hot electron propagation through the ablated plasma by monitoring the $\mathrm{Cu}-\mathrm{K} \alpha$ fluorescence of the $\mathrm{Cu}$ dopant. We discuss the modifications to the coater, the choice of the dopant and the uniformity of $\mathrm{Cu}$ content in the deposited film.

\section{FABRICATION DETAILS}

As mentioned above, the choice of the dopant is crucial for obtaining the desired films. For copper doping, obviously a copper containing hydrocarbon gas or vapor is required. Since, to the best of our knowledge such a gas or liquid does not exist we had to extend our choices to solid dopants. Previous reports in literature indicated rather successful use of copper acetylacetonate $(\mathrm{CuAcAc})^{7}$ for producing rather thin films. This material sublimates at $\sim 220^{\circ} \mathrm{C}$ and has enough vapor pressure at $\sim$ $100-150^{\circ} \mathrm{C}$ to be used as a dopant for the GDP process. However, given the high temperatures needed the use of our traditional gas delivery equipment was not possible. We therefore decided to introduce the $\mathrm{CuAcAc}$ vapor directly into the coater without the use of gas flow control equipment. The temperature of the $\mathrm{CuAcAc}$ reservoir was used to control the $\mathrm{CuAcAc}$ flow. CuAcAc was loaded into a reservoir which could be heated to $>150^{\circ} \mathrm{C}$. This reservoir was inserted into the coater and a delivery tube was added to it to allow the introduction of $\mathrm{CuAcAc}$ 
directly into the plasma. Due to the asymmetrical introduction of the dopant into the azimuthally symmetric coating chamber (Fig. 1) the dopant concentration was expected to be non-uniform. However, since the shells bounce randomly in a given area of the pan, they randomly sample areas of different $\mathrm{Cu}$ doping level very quickly. The shells take $<1 \mathrm{~s}$ to complete a full cycle during their movement in the pan. In that time $<1 \mathrm{~nm}$ of coating has been deposited, therefore the $\mathrm{Cu}$ doping level on the shells is expected to be uniform on this level. This was examined as described later on a much coarser level, $\sim 1 \mu \mathrm{m}$, which was the scale of interest for these experiments, and found to be the case. One concern was recondensation of the $\mathrm{CuAcAc}$ vapor back into the solid form upon encountering the much colder coater parts such as the bounce pan.

Coatings were initially deposited on flat substrates and the level of doping was measured using $x$-ray fluorescence (XRF) as is commonly done for the other dopants as well. The $\mathrm{X}$-ray fluorescence signal was calibrated using pure $\mathrm{Cu}$ foils of several different thicknesses to obtain the correct conversion coefficient. Also, the standard XRF analysis was performed on the films to account for absorption effects due to the finite thickness of the film and the carbon content. ${ }^{8} \mathrm{We}$ found that coatings with $<0.1$ to 3 at. $\% \mathrm{Cu}$ could be obtained on flat substrates depending on the location of the region examined relative to the delivery tube. The dopant reservoir temperature was $\sim 120^{\circ} \mathrm{C}$ for such runs. The deposited films were initially very dark depending on the $\mathrm{Cu}$ content, with films with higher $\mathrm{Cu}$ content being darker (Fig. 1). These films became more transparent over time as the $\mathrm{Cu}$ in the film oxidized. This is puzzling as copper oxide is rather dark, but this comparison may not be valid as the exact oxidation state of $\mathrm{Cu}$ in our films is

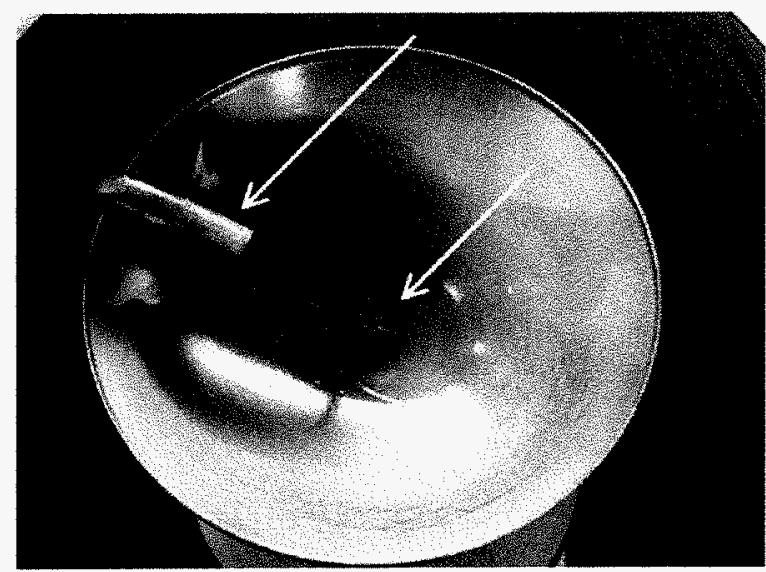

Fig. 1. A Cu-CD coated pan showing the lateral nonuniformity of the coating. The darker areas in the pan correspond to higher $\mathrm{Cu}$ content. The shells, pointed to by arrow near the center of the pan, bounce around quickly during coating and receive an average coating uniform on $\mathrm{a} \sim 1 \mathrm{~nm}$ level. The CuAcAC delivery nozzle is pointed to be the upper arrow. unknown. Another conjecture is possible hydride formation, $\mathrm{Cu}(\mathrm{I}) \mathrm{H}$, a dark red-brown compound, ${ }^{9}$ during plasma polymer deposition. This may be the cause of darkness of the as deposited film which then becomes lighter upon oxidation. The presence of oxygen in the films was confirmed by $x$-ray dispersive elemental analysis (EDAX). This oxidation did not compromise the integrity of the film at these doping levels.

$\mathrm{Cu}-\mathrm{CD}$ shells were made using the depolymerizable mandrel technique. ${ }^{10,11}$ Therefore, polyalphamethylstyrene (PAMS) shells were used as substrates for this application. When coating shells the $\mathrm{Cu}$ content was found to be $\sim 0.9$ at. \% for a delivery tube temperature of $\sim 120^{\circ} \mathrm{C}$. This was indeed what was desired. The $\mathrm{Cu}$ dopant was found to be thermally stable as its level remained the same upon removal of the PAMS mandrel at $300^{\circ} \mathrm{C}$ to leave the freestanding $\mathrm{Cu}-\mathrm{CD}$ shell.

A problem was encountered in the very beginning and the conclusion of the runs. This involved the timing of initiation and termination of the plasma relative to heating of the $\mathrm{CuAcAc}$ reservoir. Due to the fact that the reservoir does not reach the final desired temperature of $\sim$ $120^{\circ} \mathrm{C}$ instantaneously, some $\mathrm{CuAcAc}$ is evaporated at lower temperatures while the reservoir is ramping up in temperature. If the plasma if not turned on during this time the evaporated $\mathrm{CuAcAc}$ recondenses on the shells in solid form and manifests itself as crystallites embedded in the subsequently deposited $\mathrm{Cu}-\mathrm{CD}$ film. If the plasma is turned on too early, before any appreciable CuAcAc is evaporated then a thin layer of undoped or slightly doped $\mathrm{Cu}$ is deposited and will be present on the inside of the eventual shell [Fig. 2(a)]. The same situation is present at the end of the run and affects the very outside layer of the shell. A simple solution is the introduction of a shutter in the chamber over the shells. However, given the space limitations in the traditional GDP coaters this was not practical in the time scale of this development effort. In order to avoid the problem, we had to determine the proper timing to avoid crystallite formation [Fig. 2(b)]. This probably meant that there was a thin $(<0.15 \mu \mathrm{m})$ layer that had a slightly lower $\mathrm{Cu}$ content on the inside and outside of the shells produced. This was not of concern for these experiments and can indeed be avoided if required by engineering a shutter into the process. No evidence of crystallites was seen optically, interferometrically or by scanning electron microscopy (SEM).

In addition to measurements of the $\mathrm{Cu}$ at. \% of $\mathrm{Cu}$ $\mathrm{CD}$ shells by XRF which provided the average $\mathrm{Cu}$ content in the shell, they were also examined in cross-section by SEM in back scatter mode, and EDAX for local uniformity of $\mathrm{Cu}$ content in the wall. Fig. 3(a) shows a typical shell cross-section of a $\sim 7 \mu \mathrm{m}$ thick $\mathrm{Cu}-\mathrm{CD}$ shell in backscatter mode. In this mode, any major nonuniformity of $\mathrm{Cu}$ content would be evident as the $\mathrm{Cu}$ rich areas appear brighter. The uniformity of the signal indicates there is no gross non-uniformity of the $\mathrm{Cu}$ content, such as micron scale agglomeration, in the film. The film was further examined in several spots by EDAX 

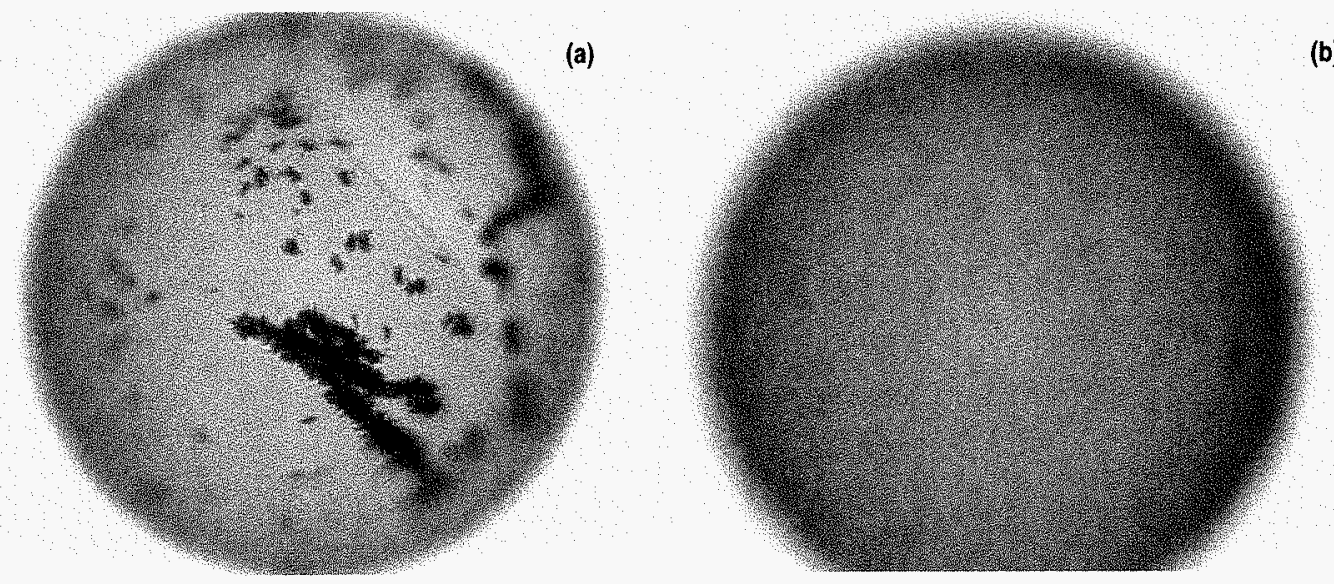

(b)

Fig. 2. (a) Crystallites of CuAcAc are formed on shells if the CuAcAc flow is present near the shells without the presence of the plasma. (b) $7 \mu \mathrm{m}$ thick $\mathrm{Cu}-\mathrm{CD}$ shell produced without any crystallites of $\mathrm{CuAcAc}$. The plasma was present during the entire coating run, dissociating the CuAcAc continuously.
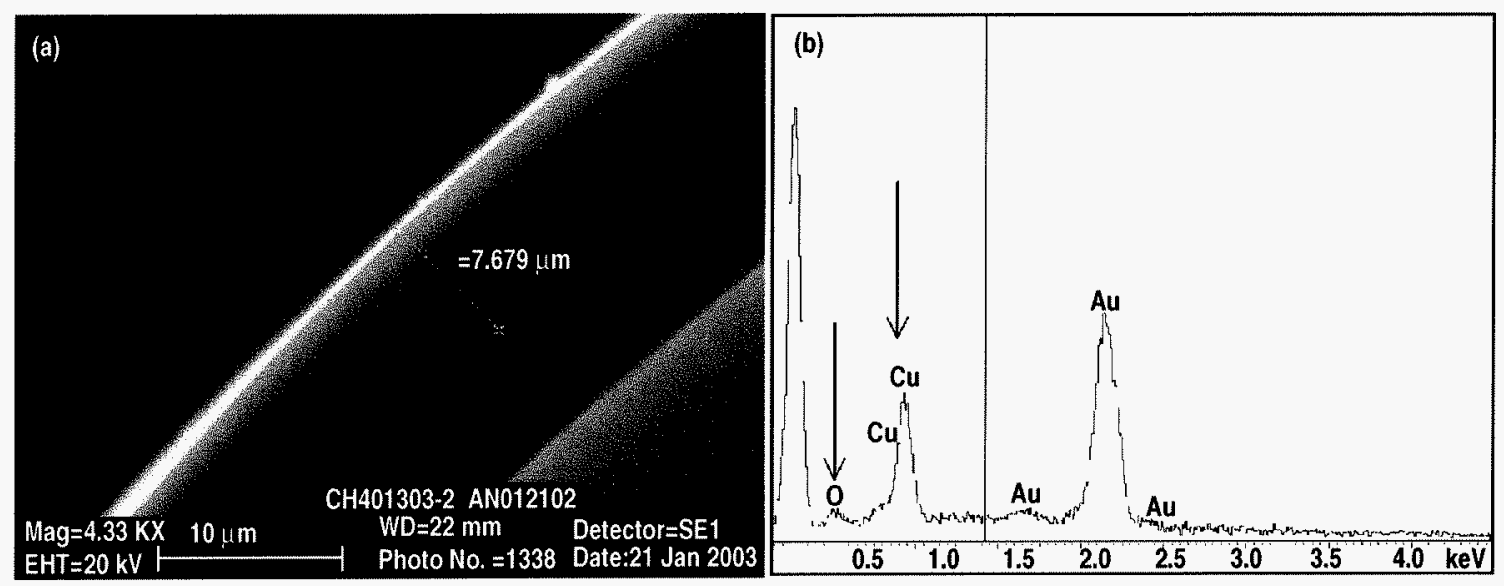

Fig. 3. (a) Cross-sectional SEM image of a typical $\sim 7 \mu \mathrm{m} \mathrm{Cu}-\mathrm{CD}$ shell taken in backscatter mode. The uniformity of the image intensity within the wall indicates the qualitative uniformity of the $\mathrm{Cu}$ content in the wall. (b) EDAX signal from the $\mathrm{Cu}-\mathrm{CD}$ shell shown in Fig. 3. Such signals were obtained across the wall at $\sim 2 \mu \mathrm{m}$ resolution and were observed to be the same indicating quantitative uniformity of $\mathrm{Cu}$ content.

[Fig. 3(b)] and the Cu signal was observed to be constant in the wall within the measurement uncertainty of $\sim 10 \%$. The surface finish of the $\mathrm{Cu}-\mathrm{CD}$ shells was measured by phase shift interferometry to be $\sim 3 \mathrm{~nm}$ RMS for $\sim 7 \mu \mathrm{m}$ thick shells (Fig. 4).

\section{CONCLUSION}

$\mathrm{Cu}$-doped CD shells have been prepared by the GDP process. $\mathrm{CuAcAc}$, a solid at room temperature, has been used as the dopant source at $\sim 120^{\circ} \mathrm{C}$ to dope GDP with as much as 3 at $\%$ on flat films and $\sim 1$ at $\%$ on shells. The dopant must be introduced directly into the plasma in order to avoid recondensation of the $\mathrm{CuAcAc}$ into crystallites. The uniformity of the copper content was examined by elemental analysis of shell wall cross-section and was found to be uniform within the measurement

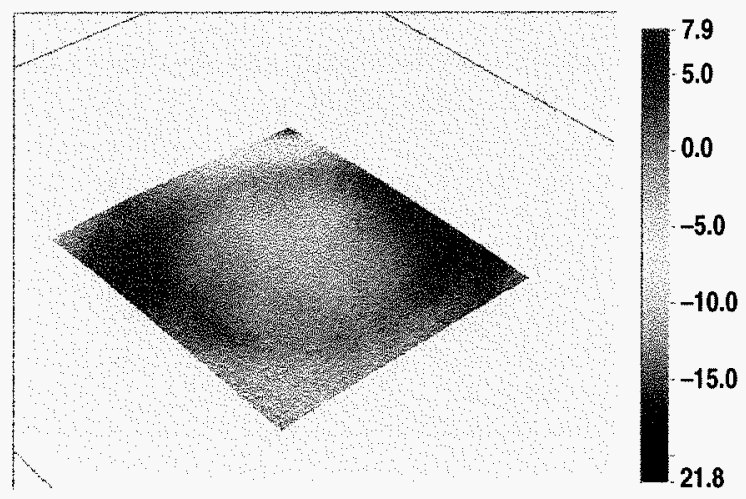

Fig. 4. Phase shift white light interferometry map of the surface of $\mathrm{a} \sim 7 \mu \mathrm{m}$ thick $\mathrm{Cu}-\mathrm{CD}$ shell. The RMS roughness was $\sim 3 \mathrm{~nm}$. 
errors of $10 \%$. The surface finish of $\sim 7 \mu \mathrm{m} \mathrm{Cu-CD}$ shells was $\sim 3$ nm RMS.

\section{ACKNOWLEGMENT}

Work supported by Department of Energy under contract DE-AC03-01SF22266.

\section{REFERENCES}

1. W.L. JOHNSON, S.A. LETTS, C.W. HATCHER, L.E. LORENSEN and C.D. HENDRICKS, "Plasma Polymerization Coating of DT-Filled Glass Shells for Laser Fusion Targets," Plasma Polymerization ACS Symp. Ser. No. 108, 315, (1979).

2. A. NIKROO, F.H. ELSNER, D.G. CZECHOWICZ, S.E. GRANT, A.L. GREENWOOD, M.L. HOPPE,

B.W. MCQUILLAN, W.J. MILLER, J.M. PONTELANDOLFO, D.A. STEINMAN, R.B. STEPHENS, K.R. SCHULTZ, M. TAKAGI, "Capsule Production and Development For ICF Experiments," Proc. of the 1st Inertial Fusion Sciences and Applications, Bordeaux, published by Elsevier Press, (2001).

3. S.W. FERGUSON, R. STEVER, and R.M. BRUSASCO, "Impedence-Power Effects on Plasma Polymer Surface Finish Using a Helical Resonator Discharge," J. of Applied Polymer Science 54, 107 (1994).

4. R. BRUSASCO, M. SACULLA, R. COOK, "Preparation of Germanium Doped Plasma Polymerized Coatings as Inertial Confinement
Fusion Target," J, of Vac. Sci. Technol. A -Vacuum Surfaces \& Films, 13 (3 Part 1): 948-951, (1995).

5. A. NIKROO, "Deposition and Characteristics of Chlorine-Doped Glow Discharge Polymer Films," Fusion Technology, Vol. 31, (no.4), p. 431-4 (1997).

6. R. BRUSASCO, S. LETTS, P. MILLER, M. SACULLA, R. COOK, "Preparation and Characterization of Beryllium Doped Organic Plasma Polymer Coatings," J. Vac. Sci. Technol. A Vol. 14, no.3, pt.1, pp.1019-24 (1996).

7. T. MARUYAMA, T. SHIRAI, "Copper Thin Films Prepared by Chemical Vapour Deposition from Copper (II) Acetylacetonate," J. Mat. Sci. 30, 5551 (1995).

8. M.L HOPPE, R.B. STEPHENS, D. HARDING, "Characterization of Chemical Dopants in ICF Targets," Fusion Technology, Vol. 31. no. 4 5045121, (1997).

9. J.A. DILTS and D.F. SHRIVER, "The Nature of Soluble Copper (I) Hydride." J. Am. Chem. Soc., 90:21, 5769, (1968).

10. S.A. LETTS, E. M. FEARON, S.R. BUCKLEY, M.D. SACULA, L.M. ALLISON, R.C. COOK, "Preparation of Hollow ICF Targets Using a Depolymerizable Mandrel," Mat. Res. Soc. Symp. Proc. 372125 (1995).

11. B.W. MCQUILLAN, A. NIKROO, D.A. STEINMAN, F.H. ELSNER, D.G. CZECHOWICZ, M.L. HOPPE, M. SIXTUS, W.J. MILLER, "The PAMS/GDP Process for Production of ICF Target Mandrels," Fusion Technology, Vol. 31, (no.4), pp. 381-4 (1997). 